\title{
Transformations in the Social Impact: Politics, Media, Social Networks
}

\author{
Svetlana Alexandrova \\ Institute of Philosophy and Sociology at Bulgarian Academy of Science
}

Трансформации в социалното въздействие: политика, медии, социални мрежи

Светлана Александрова

Институт по философия и социология при Българската академия на науките

\section{Author Note}

Svetlana Alexandrova (ii) https://orcid.org/0000-0002-2099-0967

Svetlana Alexandrova has no known conflict of interest to disclose.

Correspondence concerning this article should be addressed to Svetlana Alexandrova, Sofia 1000, 4 Serdika str., Institute of Philosophy and Sociology. Email: svetlanalex@bas.bg

\section{Бележки за автора}

Светлана Александрова (1) https://orcid.org/0000-0002-2099-0967

Светлана Александрова няма конфликт на интереси.

Кореспонденцията, свързана с тази статия да се адресира до Светлана Александрова, Институт по философия и социология при БАН, София 1000, ул. „Сердика” №4. Email: svetlanalex@bas.bg 


\begin{abstract}
The article analyzes the role of political elites and the media in shaping public opinion and the direction of public attention. Focusing on the transformations in the social impact under the influence of network culture in the online communication environment, it examines how the role of traditional structures of power is transformed, and how this affects political culture, the formation of public opinion, and its participation in socio-political life. Social networks are a means of dialogue and organization, and this requires political elites and the media to consult and comply with active public opinion in the online communication environment.
\end{abstract}

Keywords: public opinion, politics, media, social networks

\title{
Резюме
}

Статията разглежда ролята на политическите елити и медиите във формирането на общественото мнение и насоката на общественото внимание. Като се фокусира върху трансформациите в социалното въздействие под влиянието на мрежовата култура в онлайн комуникационната среда, изследва как ролята на традиционните властови структури се променя и как това влияе върху политическата култура, формирането на обществено мнение и неговото участие в обществено-политическия живот. Социалните мрежи представляват средство за диалог и организация, а това налага политическите елити и медиите да се допитват и съобразяват с активното обществено мнение в онлайн комуникационната среда.

Ключови думи: обществено мнение, политика, медии, социални мрежи

\author{
ARTICLE INFO: \\ Original Article \\ Received: 15, 01.2021 \\ Revised: 22, 02.2021 \\ Accepted: 09, 03.2021
}




\section{Трансформации в социалното въздействие: политика, медии, социални мрежи}

Процесът по формиране на обществено мнение представлява сложен, динамичен психологически и социален процес, в който основни действащи елементи са социализацията, мотивацията, информацията и комуникацията. Многобройните им употреби в рамките на различните форми на социално взаимодействие и социално влияние определят комплексното въздействие на съответстващите им променливи, в това число, очаквания, знания, интереси, обуславящи мотивацията за формиране на едно или друго мнение; представи, мисловни модели, ценности и стереотипи, приети и улегнали в хода на социализация и част от гражданската политическа култура; различните информационни знаци, сигнали и съобщения, и техните комуникационни обмени, ефекти и интерпретации. Преработването на нова информация в комуникационния процес е обвързано с множество променливи (степен на предварително знание, нагласи и интереси), които оказват влияние върху формирането на общественото мнение. В процеса на комуникация новодобитата информация си взаимодейства и филтрира не само през вече възприетата и улегнала в представите ни информация, но и със специфични информационни сигнали, характеризиращи конкретната ситуация, и които преднамерено или необмислено създават предпоставките за насочване на вниманието ни в определена посока.

В конструирането на значими за общественото мнение теми и тяхното разпространение научнообосновани фактори са политическите елити и медиите. Важна предпоставка за такава роля представлява фактът, че те разполагат с ресурсите самостоятелно и многократно повече в комбинация - да въздействат мащабно и да създават множественост, характеризираща общественото мнение и отличаваща го от частното, индивидуално мнение. От своя страна, активираните теми и реакции, публично формираните мнения биват преработени в процеса на социално взаимодействие, където определящи фактори на влияние върху общественото мнение са референтната група на индивида и лидерите на мнение.

Повсеместното приложение на дигиталните технологии и комуникационният процес в социалните мрежи, с видимото фрагментиране на различни групи, предпоставят още поясно значението на референтната група, като влиятелен фактор при формирането социалните представи и нагласи. Съвременната дигитална социална среда осигурява и нови 
възможности за изява на лидерите на мнение, като запазва важната им роля в процеса на формиране на обществено мнение. Нещо повече, за първи път виртуалното пространство позволява на реципиентите да бъдат производители и разпространители на информация, с което се разширяват както източниците на информация, така и достъпът до нея. Медийното съдържание от традиционни източници продължава своето въздействие чрез преноса му в електронна среда, но социалните мрежи допускат изява и на различни от официалните позиции възгледи и информационни аспекти, и така оказват допълнително влияние върху процеса на формиране на обществено мнение. Съществената характеристика на мрежовата култура - обменът на информация, очертава ясни възможности за изява на активното обществено мнение.

Условията, които онлайн комуникацията предоставя, създават предпоставки за разместване на традиционните властови пластове по отношение на влиянието върху политическата култура, общественото мнение и обществения дневен ред. Иницииращите общественото мнение фактори и тяхното доскорошно обективно положение на лидери във формирането на обществените представи се променя от новите възможности на комуникационната онлайн среда, която установява мрежовото хоризонтално общуване на мястото на вертикалната йерархична комуникация.

\section{Политически елити}

Особено значим фактор за формирането на обществено мнение са политическите елити (управляващата класа), които в демократичните общества си взаимодействат интензивно с общественото мнение, доколкото легитимирането на управленската им позиция се нуждае от общественото одобрение. В „Анатомия на властта“ Джон Гълбрайт отбелязва, че успешно управляващата власт зависи от манипулирането на общественото съзнание. В хода на човешката история това е постигано чрез упражняване на три типа власт, която използва негативно (наказание), позитивно (награда) и интернализирано (идейно) влияние, чрез въздействието на убеждението и образоването в определени категории и социални норми. Принуждаващата, компесаторната и условната власт се упражняват в различни форми и съчетания от съответстващите им източници - личността, собствеността и организацията (Galbraith, 1993). 
Общото и в трите случая е притежанието на необходимите властови ресурси и механизми на влияние, които гарантират доминирането на едни субекти над други. Управляващата класа, като доминираща група, концентрира икономически и информационни ресурси, които с помощта на масовите комуникации влага в упражняването на социален контрол и насочване на общественото мнение в подкрепа на поддържаните от управляващите идеи и норми. Положителните аспекти на тази постановка в дискурса на демокрацията касаят грижата на елита към мнозинството - насочването на масите към полезно обществено развитие, което е в компетенциите и възможностите на елита, в противовес на недостатъчните знания и умения сред мнозинството за посвещаване на общото благо. Отрицателните аспекти се отнасят към употребата на общественото мнение и постигането на обществено одобрение, чрез негативни социални техники за въздействие върху него и в полза на частните интереси на елита, които се налагат като обществено полезни. Теза, релевантна на вертикалния или йерархичен комуникационен процес, където политическите послания, със съдействието на масовите медии, оформят обществените нагласи и социалните норми в обществото (MCQuaill, 1992).

Подобни практики съдействат за налагане на интересите на управляващите по косвения начин на прикрити форми на убеждение. Крайните виждания в този дискурс допускат, че демокрацията всъщност не съществува, че тя играе ролята на параван, „на фасада за господството на малцинството.“ (Dahl, 2006, p. 389) В противоречие, както твърди Робърт Дал, демократичните елементи и балансът на интересите се гарантира от необходимостта малцинството да получи подкрепата на различни обществени групи, които по този начин придобиват и възможността да въздействат върху управленските политики и посоките на обществено развитие.

Един от основните начини за формиране и/или промяна на мнение, с който елитите оперират е чрез убеждаващо въздействие и техниките за социално внушение, като пропагандата, рекламата и ПР. Терминът пропаганда добива широка и негативна употреба в началото на 20-ти век, като техника за убеждаване и е особено специфичен за тоталитарните режими, докато в модерните демокрации пропагандното влияние се проблематизира през монополизирането върху формирането на общественото мнение (Hristov, 2008). 
Пропагандата, според Уолтьр Липман, е усилие да се промени представата, на която хората отговарят, техните усилия, чувства, стремежи и така, да се замести един обществен модел с друг. Колективната идея, обществото се нуждае от йерархична организация, от елит, способен на разумна преценка за обществените въпроси и не може да се очаква, нито народната воля да е сама по себе си отговорна, нито медиите непременно да ни предоставят истинна картина на външния за нас свят - и двете, по презумпция приети в демокрацията: „Да се обръщаш за помощ към обществото по всички заплетени въпроси, с които се сблъскваш, почти винаги изразява желание да се избегне критиката на компетентните чрез привличане на огромно некомпетентно мнозинство“ (Lippmann, 2001, p. 320).

Прилагането на убеждаването и пропагандата, като инструмент за управление на народа, както и идеализираната представа за ролята на елита, като защитник на общото благо, се отрича в рамките на елитистко-плуралистичния дебат. Изтъкват се възможностите за злоупотреби с управлението, опасността демократичните идеи да се използват за легитимиране на авторитарно управление и крайните форми на авторитарни и тоталитарни системи или оперирането с властта, като диктатура. Взаимният контрол на властите, плурализмът и децентрализираното вземане на решения са гарант, че повече разнородни интереси ще получат балансирано внимание и ще бъдат включени в обществено значимите процеси (Dahl, 2006).

В практиката обаче се използват прийоми за ограничаване на комуникационния процес, чрез липса на информация, подвеждаща информация, дезинформация, с оглед едно мнение да надделее над друго и това става чрез един от аспектите на убеждаването в неговата форма на манипулация, когато информацията е преднамерено интерпретирана или представяна вън от реалния си контекст, с цел създаване на заблудена представа за реалната действителност. Комуникацията, като процес на предаване на информация, цели промяна на нагласи и поради това е „естествена среда“ за възникване и функциониране на манипулацията (Bondikov, 2011). Обикновено манипулацията е тайна, за да бъде постигнат търсеният ефект, но Венцеслав Бондиков обръща внимание, че тя може да бъде и явна, като в този случай значение за въздействието й има публичността. Използването на медиите, като канал за разпространение, публичното й представяне я правят ефективна и валидна, защото достоверността на информацията е потвърдена от представянето й от авторитети - 
медии, лидери на общественото мнение, експерти. Според автора, въздействието на манипулацията служи за утвърждаване (стабилизиране), за модифициране (малки изменения) и за конверсия (отказ от предишни и изграждане на нови) мнения (Bondikov, 2011). Сама по себе си манипулацията има положителен ефект върху постигането на съгласие в обществото и не представлява непременно отрицателен процес на влияние, защото е въпрос на избор дали реципиента ще я приеме или на свой ред ще манипулира. Авторът посочва, че можем да разглеждаме отказа от гласуване като начин да не бъдем манипулирани толкова лесно, предвид често неизпълнимите обещания в предизборните кампании, което потвърждава идеята, че „манипулацията допуска двойно (двупосочно) въздействие“" (Bondikov, 2011, p.70).

Голямо значение в отношението между елити и обществено мнение е отредено и на ролята на авторитета като лидер. Авторитетът се характеризира със силна увереност. Понятието има широк обхват и включва сила, принуда, убеждаване, но и призвание приемане на базата на признание и консенсус. Според Серж Московичи в основата на всяка власт стои авторитетьт в ролята му на водач, лидер, който води масите в масовото общество, използва внушението за изграждане на общи социални представи и притежава харизма свойството да управлява като призвание свише, мисия или духовна задача (по Вебер). Серж Московичи изтъква, че разширяването на сферите на комуникациите и на общественото мнение усилват монопола на авторитета, защото ускоряват „производителността на системите на имитация и конформизъм“ (Moskovici, 2007, p. 158). Масите се подчиняват и преклоняват пред водачите - носители на идеите и на „свойството на споделената илюзия“ (Moskovici, 2007, p. 172) Според произхода на авторитета, Московичи извежда два типа авторитет: авторитет на функцията - легитимен, определен от традицията, от титлата, например благородническата титла в миналото и авторитет на личността - действащ в масовото общество, нетраен, определен от дарбата, с изкуствена и наложена легитимност. Единственият възможен авторитет в масовото общество, поради неговата неустойчивост и процес на непрекъснато развитие, е авторитетьт на личността (Moskovici, 2007).

Като разглежда връзката между манипулация и харизма, Венцеслав Бондиков обрьща внимание, че харизмата и имиджът се характеризират с възможността да влияят върху големи групи хора, като възникват, когато в обществото се създадат условия за 
социално-психологическа потребност от тях, а моралният аспект на действията на носителите им не е от значение. За разлика от харизмата, личността „икона“ не се характеризира с такава голяма подкрепа, а само в рамките, в които е призната (Bondikov, 2011). Авторът определя авторитета като неформално, понякога неосъзнато влияние, чието упражняване е чрез доброволно подчинение от другите в групата на базата на признатите лични качества на носителя на авторитет, неговите знания и умения, които за околните имат значение и валидност и те ги приемат за по-правилни от собствените си оценки. „Авторитетът означава да накараш другите да променят своите позиции чрез влиянието, което имаш над тях.“ (Bondikov, 2011, р.337) Естественото въздействие на авторитета се отличава и в подражанието, което Бондиков определя като „усвояване на социален опит, моделиране на поведението или идентифициране с някаква конкретна значима личност“ (Bondikov, 2011, p.100). Така престижът на лидерите, включително и социалната приемливост на лидерската позиция е достатъчна причина тя да бъде приета от масата индивиди, когато няма установено мнение или дори да противоречи на вече утвърдени мнения.

В информационното общество функцията на авторитета е обвързана с експертизата, със специфични знания и умения, но в същото време с началото на постмодернизма приключват както метаразказите и идеологиите, упльтняващи фигурата на лидера водач, така и признанието пред авторитета, като отличаващо го знание - истините са частни, а всеки е авторитет сам за себе си. Нещо повече, дигиталните комуникационни практики позволяват всяка частна истина да бъде и публично достъпна. В публичното пространство преекспонирането на демократичния принцип за равностойност на мненията приравнява тежестта в позициите на компетентния специалист и слабо осведомения лаик. Тези тенденции се засилват още повече в размитото въздействие, което произвежда комуникационният процес във виртуалното пространство, докато в политически план се откроява друг проблем на демокрацията, какъвто е популизмът или политическите действия, ръководени от общественото мнение. Включващите практики, характерни за мрежовата комуникация в интернет, извеждат значението на влиянието на групата и размиват влиянието на политическите елити върху процеса на формиране на обществено мнение.

Postmodernism Problems / Проблеми на постмодерността Vol. 11, No. 1, 2021, ISSN: 1314-3700, https://pmpjournal.org https://doi.org/10.46324/PMP2101058 


\section{Медии}

Концепциите за влияние на медиите върху обществените представи и нагласи обхващат няколко подхода. Първоначално влиянието на традиционните медии е оценено като основен механизъм за мащабно влияние върху обществото и пропагандиране на политическите идеи. Поради ограниченото ни знание, общественото мнение отговаря на псевдосреда, която се конструира от информационните медии и така влияе върху нашата представа за света около нас (Lippmann, 2001). В този дискурс от 20-те години на 20 век научните търсения са ориентирани от т. нар. хиподермичен модел на комуникацията, при който масовите комуникационни средства са смятани за оказващи огромно въздействие върху хората, оприличавано на магически куршум, който е способен автоматично да контролира и променя една пасивна и беззащитна публика (Schramm, 1992). Със средствата на пропагандата и масовите комуникации - посредник между управляващите и обществото, общественото мнение е насочвано да поддържа безкритично съществуващия социален ред или промяната в статуквото. Такива изследвания са предмет и на Франкфуртската школа, където социалната критика е насочена срещу влиянието на масовите комуникации, които съдействат за уеднаквяване и едноизмерно мислене и поведение, ефективно сливат в едно развлечение и манипулация, заличават индивидуалната мисъл и унищожават общественото мнение, отнемат действителния контрол на гражданите над властта и едновременно с това се превръщат в най-ефективния политически инструмент. „Едноизмерната мисъл систематично се подкрепя от онези, които правят политиката, и техните доставчици на масова информация. Техният дискурсивен свят е населен от самодоказващите се хипотези, които, непрестанно и монополно повтаряни, стават хипнотични дефиниции или диктат“ (Marcuse, 1997, p. 33).

По-късно тезата за лесно контролираната и безащитна публика е изместена от идеите за активни публики, които сами подбират колко и какво външно влияние да допуснат, когато изграждат нагласите си. Комуникираните от медиите съобщения нямат силата на междуличностните отношения в процеса на формиране на мнение, възприемат се различно от различните социални категории, а ограничените им ефекти действат само индиректно, най-вече при подкрепа на статуквото и създаване на общоразпространени образи и нагласи за нови факти и събития (Katz \& Lazarsfeld, 1957). Тези открития оформят концепцията за 
ограничените ефекти на медиите, която признава, че масовите медии имат усилващ ефект върху предварително установените ни нагласи и стимулиращо въздействие, изразяващо се в активна употреба на новини, подкрепящи съжденията ни, но не представлява изцяло контролираща общественото съзнание сила. Според Уилбър Шрам най-значима промяна в комуникационната теория представлява идеята, че публиката не е пасивна, а напротив пълноценен партньор в комуникационния процес; силно активна и селективна публика, която по-скоро манипулира информацията, отколкото е манипулирана от нея (Schramm, 1992). С други думи, публиката употребява медийното съдържание, като го интерпретира различно на индивидуално ниво и съобразно собствените си потребности. Идеята за застрашителната сила на масовите комуникации се основава на голямото време, което хората им отделят, за забавление или информация, но в крайна сметка те не се възползват сляпо от това, което им се предлага, напротив, търсят това, което желаят да получат, а поради откъснатостта на масовите средства и изолирания от тях начин на възприятие на съобщенията им, хората ги преработват в социалните групи на които принадлежат, като разчитат на авторитетите в обкръжаващата ги среда (Schramm, 1992). Въздействието на медиите не се осъществява пряко, а е подвластно на груповата динамика и опосредствано от комуникационните процеси в социалните мрежи на индивидите. В тях с най-висока степен на влияние се открояват лидерите на мнение - индивидите, които се интересуват, интерпретират, ориентират тези, които са по-пасивни и незаинтересовани и така играят решаваща роля във формирането на тяхното мнение във всекидневието. Определящата роля на този фактор произтича и от това, че мненията в най-голяма степен съвпадат с поведението поради тяхното интернализиране. Силно влияние оказват близкият, непреднамерен комуникационен процес в социалните групи, авторитетите и ефектьт на мнозинството, желанието да сме в унисон със схващанията и в разбирателство с околните, да получаваме тяхната подкрепа и емпатия (Katz \& Lazarsfeld, 1957).

Конкретното въздействие на масовите комуникации се свежда до насочване на вниманието в предполагаемо значими за обществото теми, проблеми и фигури. Тази проблематика представлява интерес за Максуел Маккомс и Доналд Шоу, които развиват т. нар. Agenda setting, теория за медийните ефекти върху формирането на общественото мнение в рамките на индиректното въздействие. Поставяйки важните въпроси, които си 
струва да влязат в „публичния дневен ред“ - не толкова какво, а за какво да се мисли, медиите организират тематично дневния ред на обществото и този ефект въздейства независимо от индивидуалното възприятие, нюансирано от социалната среда на индивида (McCombs \& Shaw, 1972). Ефектите на медийното съдържание се проявяват в начина, по който си представяме света (по Липман), кои въпроси са важни и кои проблеми, в каква степен ще бъдат предмет на интерес. Включването и подредбата на проблемите в новините на практика насочва възприемането им като приоритетни и обществено значими, като вниманието на общественото мнение нараства успоредно с вниманието на медиите към даден социален проблем. В рамките на тази парадигма са отличени допълнителните ефекти на въздействие на медиите върху обществения интерес чрез наблягането на даден проблем или политик, правенето му значим от медиите (priming) и контрола върху перспективата, рамкирането на аспектите и детайлите (framing), през които да мислим проблема. И двете понятия имат роля в конструирането на стандартите, които организират отношенията, оценките и нагласите в обществото. Макар и косвено медийното въздействие върху общественото мнение очертава кои са ключовите обществени проблеми, кои аспекти от тях са предмет на обществения интерес и как те се отразяват в отношението ни към политическите лидери (Iyengar, 1990; Clawson, Oxley, 2016). В този смисъл въпросите за собствеността на медиите и политическото влияние върху тях проблематизират упражняването на саморегулиращите демократични принципи на медиите за обективност, точност, фактологичност и равностойност в представянето на различни гледни точки при оформянето на медийното съдържание.

Намеса в това отношение се наблюдава с увеличаващата се употреба на дигиталните технологии и комуникационния процес в социалните мрежи, които предпоставят важна трансформация от вертикално към хоризонтално циркулиране на информацията. Позволяват реципиентите да бъдат производители и разпространители на данни, да коментират, уточняват, критикуват или опровергават информацията от политическите елити и от медиите. В резултат, влиянието на тези фактори върху общественото мнение е по-неопределено и колебливо. Тези нови форми на комуникация разширяват източниците на информация и достъпа до нея, разместват традиционното йерархично влияние и го заместват с мрежово въздействие, където груповото мнение е отправна точка за 
допускането и интерпретацията на информацията. Медийното съдържание от традиционни източници продължава своето въздействие чрез преноса му в дигитална среда, но мрежовата комуникация, сред изобилието от информация, допринася за достьпа до различни гледни точки, непрекъснато обогатяване с нова информация, спомага индиректното опознаване на даден проблем и в резултат, оказва допълнително въздействие върху формирането на обществени нагласи.

\section{Онлайн комуникационната среда}

По данни на Евростат за 2019 г. достьпът на домакинствата в ЕС до интернет ресурси варира в границите 75-98 \%, регулярните (поне веднъж седмично) потребители в мрежата между 16 и 74 години са 84 \%, а една от най-честите активности е участието в социални мрежи - 54 \% (Eurostat, 2020). Вече установената комуникационна среда, с повсеместната и тенденциозно нарастваща употреба на интернет и социалните мрежи, е снабдена с инструменти за лесно социално взаимодействие и бърз достъп до данни. Тези характеристики променят ролята на разгледаните властови аспекти на политическите елити и медиите по отношение на влиянието им върху формирането на общественото мнение. На първите се налага да създават доверие и обществено одобрение в една сравнително прозрачна среда на множество леснодостьпни и взаимодействащи си информационни субекти, докато медиите са поставени в ситуация на пряка конкуренция с онлайн гражданската журналистика, която предлага автентично съдържание, неподвластно на формите на цензура и контрол, приложими към традиционните медии. От своя страна, изявите на общественото мнение в онлайн среда са много по-достъпни и видими за политиците, за медиите и за обществеността. Онлайн комуникационната среда, хаотична, саморегулираща се и хиперсвързана, в целостта си осигурява място за израз и споделяне на новини, идеи, впечатления и емоции, интереси и информация от потребителите. Активното обществено мнение и нагласи, темите от обществения живот, които привличат общественото внимание са двигатели на обществено мнение в онлайн социалния живот на виртуалните общности и биват подхранвани от особеностите на мрежовата култура в процеса на възпроизводство на информация. Споделянето на адекватна на общи цели и интереси информация, мобилизирането на усилия и ресурси в защита на интересите на своите са отличителните характеристики на мрежите. Още повече, с развитието на 
технологиите, мрежовата култура е организирана около лесен и бърз пренос на информация, преодоляване на традиционни граници в общуването, възможност за ангажимент и обратна връзка (Stoichkova, 2020).

Спецификата на социалните платформи е ориентирана към опознаване на потребителските нагласи, поради което наблюдаваните трансформации в тях, обусловени от използването на комуникационната онлайн среда, могат да бъдат релевантни към промените в начините, по които се формират социалните нагласи и общественото мнение. По дефиниция политическият маркетинг следва постулатите на икономическия маркетинг, като използва присъщите му техники, за да привлече обществена подкрепа към кандидата и да го отличи от останалите политически кандидати, програми и идеи. И на икономическия, и на политическия пазар основната цел на въздействие е общественото мнение и формирането на положителни обществени нагласи.

В „Маркетинг 4.0: От традиционното към дигиталното“ Филип Котлър, Иуан Сетиуан и Хермауан Картаджая дават детайлна картина на промените в потребителското поведение вследствие на употребата на интернет и социалните мрежи. Според авторите, виртуалното пространство се характеризира с две важни черти, които го отличават в голяма степен от традиционните комуникационни практики, целящи привличане на внимание и убеждаване: свързаност и прозрачност. В тези рамки общественото мнение е активна комуникационна мрежа и успешното влияние върху него, създаването на доверие, изисква автентичност и взаимодействие, докато цензурирането на съдържание влияе върху правдоподобното представяне и заслужаването на доверие (Kotler, Kartajaya, Setiawan, 2016). Проектирането отвън, според авторите, става много по-трудно, защото хората се свързват в мрежа, където активно коментират и споделят мнение, а когато формират нагласа се доверяват и приемат въздействие много повече от „мъдростта на тълпата“, отколкото от външни на мрежата и традиционни източници, като лидера, експертизата, медията, рекламата или ПР. „Мъдростта на тълпата“ или общественото мнение, като достоверен източник, е подкрепено от характеризиращата онлайн средата мобилност, която осигурява съучастие и автентично преживяване на събития; масов обхват, който осигурява споделеност и взаимоотношения, които не са ограничени от географски и демографски бариери; равнопоставеност, чрез допускане на алтернативни източници на информация, 
повече участие и възможност за организация на опозиционни сили и идеи; автентичност на информацията, за която немалка роля играе усещането за близост в общността. Доверието в комуникацията в социалните платформи излъчва f-факторът, като авторитет и източник на достоверна информация, докато традиционното влияние при формирането на мнение от кампании и експертни познания бива ограничено. F-факторът, описан от авторите, като включващ приятели /friends/, семейства /family/, фенове във Facebook /Facebook fans/, последователи в Twitter (followers), представлява крьгът на близките и познатите, който заема важна роля във формирането на мнение. Знанието на социалния кръг служи за защита от подвеждаща и фалшива информация (Kotler, Kartajaya, Setiawan, 2016). Именно към разрушаването на доверието в социалните общности са насочени и новите инструменти за онлайн манипулация, като троловете, фалшивите новини и целият арсенал на политиката на пост истината, които водят до дезориентация и дестабилизация на обществото, несигурна преценка на индивида, отчуждение на различните групи и социална аномия. Освен тази проблематика, критично настроените изследвания на комуникацията в интернет адресират отново положителните й аспекти, но с обратен знак.

Свързаността в интернет може да бъде разглеждана като предпоставка за увеличаващ се социален конформизъм, тъй като предоставя картина на социалното, която е подкрепена от груповото сходство в мненията, но от друга страна, затварянето в обособени виртуални пространства изключва дебата с останалите крьгове и води до фрагментаризиране и групово капсулиране на мненията, а това възпрепятства продуктивното взаимодействие и постигането на консенсус между отделните групи в обществото. Нормативното и информационно социално въздействие, което протича в групите, както и активното вътрешно конструиране на норми в тях, чрез споделянето и възпроизводството на значения, вярвания и групови стереотипи създават частни за групата перманентни образци на мнение и поведение, които не позволяват постигането на съгласие в по-голям мащаб, а водят до поляризация в нагласите. Социалното въздействие в груповите онлайн дискусии успява да създаде общ аргументативен климат на мненията, който оформя груповия тон и на базата на идентификация с групата, влияе индиректно, като привлича подкрепа от членовете си и въздейства на неутралното мнение в съответна на груповата дискусия посока (Price, \& Cappella, 2006). В допълнение, критиците на мрежата обръщат 
внимание, че в двойната логика на свързаността, обратната страна на мрежовия индивидуализъм е обвързана с понятието „автоматизирана свързаност“, като дори можем да говорим за “мрежова атомизация“ или „,автоматизирана персонализация“. В рамките на тази тенденция изпъква противоречието, че положителната перспектива за свързаност между единомишленици бива проблематизирана като нарушена поверителност или търговска експлоатация на потребителска информация. Поверителността често се жертва заради свързаността, а предоставените данни осигуряват ресурс за проучване, информация и за употреба на властови механизми за влияние върху сегменти от населението или върху цялото общество. Същностните елементи на социалните платформи - програмиране, влияние, свързаност и добиване на потребителски данни, оформят значението им в процеса на формиране на обществено мнение, улавяйки тенденциите в актуално време на неформалните и групови мнения, т. нар. ехо камери. Възможността да бъдат оценени и анализирани, определя и възможността да бъдат повлияни. Това обаче насочва към предупреждението, че влиянието върху обществените ценности и представи в мрежовото общество е смес от традиционното влияние на елити и медии и от активната динамика на взаимодействие в социалните платформи, със значителен краен ефект на размиване на отговорността при смесването на онлайн и офлайн инструменти за насочване на общественото мнение (Van Dijck, \& Poell, 2013). Алгоритмите в социалните мрежи представляват набори от кодирани инструкции, предлагащи социални отношения базирани на данни, като по този начин бива насочвано потребителското поведение, съдържанието и взаимоотношенията в социалните платформи. Програмирането и инструментализирането на експертизата и научните доказателства в дискурса на масовите медии и Agenda setting е заменено от нова пардигма на алгоритмично оценяване на информацията, което означава, че индивидуалният избор се обработва незабележимо и автоматично. Потребителските възможности за свободен избор и противопоставяне срещу насочено програмиране на обществените нагласи се свеждат, подобно на властта на управляващият дистанционното на телевизора, до частната алтернатива да не се употребяват платформите или да се подбира внимателно информационния поток и разнообразието в пропускливостта на информацията. Въпреки това, можем да говорим за автономност в социалните мрежи в по-голяма степен, отколкото при традиционните източници на влияние върху общественото мнение, именно 
защото редакцията или цензурата не са непреодолими, а свързаността, диалогичността и организацията, като присъщи елементи на онлайн комуникационната среда, трансформират условията и правилата за социално взаимодействие - в ежедневието, в неформалните взаимоотношения, но и в публичните структури и социалната комуникация, създавайки сериозни предизвикателства пред политическите елити и традиционните медии (Van Dijck, \& Poell, 2013).

Пряко въздействие върху общественото мнение в дигиталната среда на общуване има сравнителната равнопоставеност на източниците на информация. Критиките срещу този аспект се отнасят към изобилието на информация, която трудно бива пресявана от обикновения потребител в интернет. Равнопоставеността наистина допуска достьпа до различно съдържание и в същото време размива стойността на информацията, така както и отговорността при разпространението й в онлайн среда: разграничението между факта, аргументирания анализ и мнението не е толкова ясно отличимо, колкото при традиционните източници на значима информация - експертиза, институция, медиа, но еднопосочната информация от пиедестала на статуквото не успява да запази властовата си позиция в диалогичната среда на социално взаимодействие, характеризираща социалните мрежи. С лекота частното мнение става публично, а потребителските компетенции за различаването на мненията от фактите са поставени все по-често под въпрос. Друга черта на социалните платформи - достъпността размива още повече значимостта на политическите новини, които могат както да бъдат получени по всяко време в социалните мрежи, така и игнорирани, поради информационно пренасищане. Достъпността на информацията и скоростта, с която се разпространява нова и нова информация създава условия за смесване на факти и тяхното представяне и в крайна сметка, дезориентира и води до липса на консенсус относно фактите и тяхната значимост (Delli, \& Williams, 2001). По този начин еднопосочното влияние от елит и медии губи очертанията си в публичността на социалните мрежи, където информацията е опровергавана, допълвана и критикувана. Леснодостьпната и бързообновяваща се информация води до информационно пренасищане и по-трудно отсяване на съществените данни. Нито медиите, нито политическите елити са обособени и категорични фактори в създаването на съдържание - системата е пропусклива и за нови участници, носители на нов или различен прочит, които могат да влияят върху настройката 
и рамкирането на политическата програма, обществения дневен ред, върху изграждането на обществени ценности и политически смисъл.

\section{Заключение}

Трансформациите в социалното въздействие включват в голяма степен нарастващата роля на общественото мнение, като фактор в управленските и информационни практики. Йерархичният подход, разчитащ на ресурсите за мащабно въздействие, отстъпва на хоризонтален подход, който изисква повече диалогичност и прозрачност, като допуска коментарите, критиката и изявата на мнение в мрежата. Ако преди възхода на онлайн комуникацията еднопосочната информация от политическите елити и медиите определя едно по-скоро пасивно обществено мнение - реципиент на властовите позиции, то в условията на изобилие от бързодостъпна информация в глобалната мрежа и мигновенно взаимодействие и реакция в социалните мрежи, изпъква активното обществено мнение. Действително, то по-често е неструктурирано и поляризирано, а продуктивността на социалното взаимодействие в мрежата често бива подлагана на критика, но социалните мрежи са опосредстващ инструмент за диалог и организация и това налага във все по-голяма степен политическите елити и медиите да се допитват и съобразяват с общественото мнение в онлайн комуникационната среда. Тази тенденция въвежда нови правила при оформянето на обществения дневен ред, значимите теми и обществени ценности и включва в по-голяма степен общественото мнение, като ключов актьор в социалното поле.

\section{Използвана литература}

Bondikov, V. (2011). Manipulatsia i publichna komunikatsia: mitove i realnosti [Manipulation and public communication: myths and realities]. Paradoks.

Clawson, R. A., \& Oxley, Z. M. (2016). Public opinion: Democratic ideals, democratic practice. CQ Press.

Dahl, R. A. (2006). Demokratsiyata i neynite krititsi [Democracy and Its Critics]. Kritika i humanizam.

Delli Carpini, M. X., \& Williams, B. A. (2001). Let us infotain you: Politics in the new media age. In W. L. Bennett, \& R. M. Entman (Eds.), Mediated politics: Communication in the future of democracy (pp.160-181). Cambridge University Press. Retrieved from http://repository.upenn.edu/asc_papers/14 
Eurostat. (2020). Digital economy and society statistics - households and individuals. https://ec.europa.eu/eurostat/statisticsexplained/index.php?title=Digital_economy_and_society_statistics__households_and_individuals\#Internet_usage

Galbraith, J. (1993). Anatomia na vlastta [The anatomy of power]. Hristo Botev.

Hristov, Ch. (2008). Ubezhdavane i vliyanie. [Persuasion and influence]. Siela.

Iyengar, S. (1990). Framing responsibility for political issues: The case of poverty. Political Behavior, 12(1), 19-40. https://doi.org/10.1007/bf00992330

Katz, E., \& Lazarsfeld, P. F. (1957). Personal influence - the part played by people in the flow of mass communication. The Canadian Journal of Economics and Political Science 21(6). https://doi.org/10.2307/139030

Kotler, P., Kartajaya, H., \& Setiawan, I. (2016). Marketing 4.0: Moving from traditional to digital. John Wiley \& Sons.

Lippmann, W. (2001). Obshtestvenoto mnenie. [Public opinion]. LIK.

Marcuse, H. (1997). Ednoizmerniyat chovek. [One-Dimensional Man]. Hristo Botev.

Moskovici, S. (2007). Erata na talpite. Istoricheski traktat po psihologia na masite [The age of the crowd: a historical treatise on mass psychology]. Damyan Yakov.

McCombs, M. E., \& Shaw, D. L. (1972). The agenda-setting function of mass media. Public Opinion Quarterly, 36(2), 176. https://doi.org/10.1086/267990

MCQuaill, D. (1992). Masova komunikatsia. [Mass communication]. In R. Bobchev (Ed.), Communication. SU” Kl. Ohridski” Publishing house.

Price, V., Nir, L., \& Cappella, J. N. (2006). Normative and informational influences in online political discussions. Communication Theory, 16(1), 47-74.

https://doi.org/10.1111/j.1468-2885.2006.00005.x

Schramm, W. (1992). Harakter na komunikatsiyata mezhdu horata. [Nature of communication between people]. In R. Bobchev (Ed.), Communication. SU Publishing House.

Stoichkova, T. (2020). Pogled kam harakteristikite na mrezhite v izkustvata. [A look at the characteristics of networks in the arts]. Nota Bene, 50 (20). http://notabenebg.org/read.php?id=1066

Van Dijck, J., \& Poell, T. (2013). Understanding social media logic. Media and Communication, 1(1), 2-14. https://doi.org/10.17645/mac.v1i1.70 